\title{
Transactions
}

Cite this: Dalton Trans., 2012, 41, 1134

wWW.rsc.org/dalton

COMMUNICATION

\section{Multi component self-assembly: supramolecular organic frameworks containing metal-rotaxane subunits (RSOFs) $\dagger$}

\author{
Han-Yuan Gong, ${ }^{a}$ Brett M. Rambo, ${ }^{a}$ Cory A. Nelson, ${ }^{a}$ Won Cho,${ }^{b}$ Vincent M. Lynch, ${ }^{a}$ Xiaoyang Zhu, ${ }^{a}$ \\ Moonhyun $\mathrm{Oh}^{* b}$ and Jonathan L. Sessler ${ }^{* a, b}$
}

Received 8th August 2011, Accepted 15th November 2011

DOI: $10.1039 / \mathrm{c} 1 \mathrm{dt1} 1495 \mathrm{f}$

A facile, one-pot synthesis of rotaxanated supramolecular organic frameworks (RSOFs) is reported. These systems consist of bis-carboxylate anions threaded through the core of tetraimidazolium macrocycles. Trivalent metal cations, yttrium(III) and smaller lanthanides, are used to "lock" the threaded strut in place. This results in the formation of threedimensional RSOFs.

\section{Introduction}

The use of molecular building blocks to generate complex molecular frameworks is a rapidly evolving approach to structural design. ${ }^{1}$ Typically, self-assembly events, involving well-defined interactions, such as hydrogen bonding, ${ }^{2}$ metal coordination, ${ }^{3}$ and other recognition patterns ${ }^{4}$ have been used to organize the individual building blocks. This has led to the generation of a wealth of 2D and 3D molecular architectures. The incorporation of strategically designed building blocks that aggregate through either specific or selective binding interactions can be used to engineer, and in some cases predict, the nature of supramolecular aggregation. ${ }^{5}$ However, as the number of constituent species and associated bonding interactions increases so does the complexity of the resulting self-assembled systems. This makes achieving control over the resulting frameworks and their rational design a persistent challenge. One way to address this challenge is to use several disparate non-covalent binding interactions concurrently.

Metal cation coordination ${ }^{6}$ and hydrogen bonding ${ }^{7}$ are among the most important non-covalent interactions that have been used to date to stabilize self-assembled structures. These versatile binding interactions have been used separately and in tandem to generate a variety of complex architectures including metalorganic frameworks (MOFs), ${ }^{8}$ supramolecular organic frameworks (SOFs), ${ }^{9}$ and a wealth of other molecular networks. ${ }^{10}$

${ }^{a}$ Department of Chemistry \& Biochemistry, 1 University Station A5300, University of Texas at Austin, Austin, Texas, 78712-0165, USA. E-mail: sessler@mail.utexas.edu

${ }^{b}$ Department of Chemistry, Yonsei University, Seoul, 120-749, Korea. E-mail:moh@yonsei.ac.kr

$\dagger$ Electronic supplementary information (ESI) available: Additional synthetic details, spectroscopic information (NMR and MS), and crystallographic data. CCDC reference numbers 824440-824442 and 838076838077. For ESI and crystallographic data in CIF or other electronic format see DOI: $10.1039 / \mathrm{cldt} 11495 \mathrm{f}$
Separately, the use of mechanical bonds has permitted the stillnew chemistry of interlocked systems to be developed in recent years. ${ }^{11}$ Such developments have led to the generation of dynamic molecular assemblies that contain the innate ability to "do work" in the form of molecular motion. ${ }^{12}$ However, to date only a few self-assembled systems have been reported that contain metal-cation coordination, hydrogen bonding, and mechanical bonds within a single supramolecular architecture. ${ }^{1,13}$ Herein, we describe the development of such systems from a facile one-pot reaction involving trivalent cations (Y(III), Gd(III), Er(III), Tm(III) or $\mathrm{Lu}(\mathrm{III})$ ) in conjunction with the terephthalate dianion and a large tetraimidazolium "molecular box", the tetracation $\mathbf{1}^{4+}$. As detailed below, this allows for stabilization of a new class of rotaxanated supramolecular organic frameworks (RSOFs).

\section{Results and discussion}

The molecular box used for the present study, the tetraimidazolium macrocycle, $\mathbf{1}^{4+}$ (studied as its $\mathrm{PF}_{6}{ }^{-}$salt), was recently reported by our group. ${ }^{14}$ It was found to interact with the terephthalate dianion (2), but to bind this species in an "outside binding" mode. In contrast, a pseudorotaxane structure was formed when $\mathbf{1}^{4+}$ was treated with the terephthalate monoanion $\left(2 \cdot \mathrm{H}^{+}\right)$. This finding led us to postulate that incorporation of cationic species (e.g., $\mathrm{H}^{+}$, metal cation, etc.) could lead to the stabilization of higher order interpenetrated structures. In fact, we subsequently succeeded in using $\mathbf{1}^{4+}$ and 2,6-naphthalene dicarboxylate dianion to prepare two different kinds of metal-linked pseudorotaxane containing structures, namely linear metal-linked polymers based on $\mathrm{Ag}^{+15}$ and metal-stabilized 3-D metal-organic rotaxane frameworks (MORFs) based on $\mathrm{Zn}^{2+} .{ }^{16}$ We have now found that by using $\mathbf{1}^{4+}$, the terephthalate dianion $\mathbf{2}$, and an appropriately chosen trivalent cation, namely Y(III), Gd(III), Er(III), Tm(III) or Lu(III), it is possible to isolate a new class of interpenetrated structures wherein the metal cation does not play a direct role as a linker, but rather combines with hydrogen bonding interactions to stabilize a complex 3-D assembly consisting of a rotaxanated supramolecular organic framework (RSOF) as shown in Fig. 1. The subunits of the resulting frameworks described herein consist of discrete [2]rotaxane structures constructed using the molecular box $\mathbf{1}^{4+}$.

On the basis of single crystal X-ray diffraction analyses (discussed further below), the rotaxane structures that are presumably formed initially upon mixing tetracationic macrocycle 


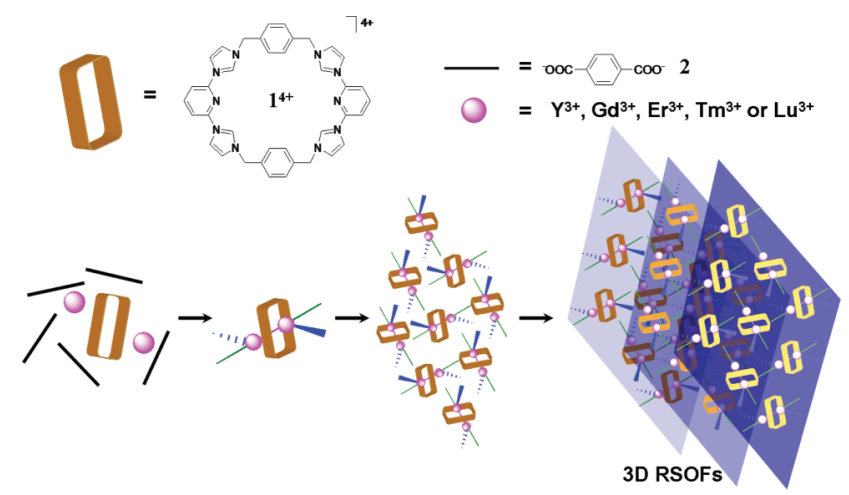

Fig. 1 Schematic representation of the principle binding interactions that stabilize the metal cation-containing RSOFs (RSOF-M, M $=\mathrm{Y}, \mathrm{Gd}$, $\mathrm{Er}, \mathrm{Tm}$ or $\mathrm{Lu}$ ) formed from $\mathbf{1}^{4+}$, terephthalate dianion $\mathbf{2}$, and a trivalent lanthanide cation, $\mathrm{M}^{3+}$. Note that different colors are used for the linkage anions to illustrate the different local chemical environments and different shadings are used to aid in the visualization of the individual 2D layers that make up the overall 3D RSOFs.

$\mathbf{1}^{4+}$, dianion $\mathbf{2}$, and the trivalent yttrium(III), gadolinium(III), erbium(III), thulium(III) or lutetium(III) cations, undergo further hydrogen bond-mediated self-assembly to form supramolecular organic frameworks. These frameworks, $\left[\mathbf{1}^{4+} \cdot(2)_{5} \cdot \mathrm{Y}_{2} \cdot 8 \mathrm{H}_{2} \mathrm{O}\right] \cdot 31 \mathrm{H}_{2} \mathrm{O}$

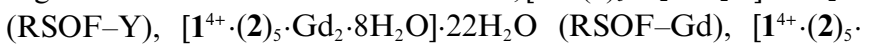
$\left.\mathrm{Er}_{2} \cdot 8 \mathrm{H}_{2} \mathrm{O}\right] \cdot 19 \mathrm{H}_{2} \mathrm{O} \quad(\mathrm{RSOF}-\mathrm{Er}), \quad\left[\mathbf{1}^{4+} \cdot(\mathbf{2})_{5} \cdot \mathrm{Tm}_{2} \cdot 8 \mathrm{H}_{2} \mathrm{O}\right] \cdot 32 \mathrm{H}_{2} \mathrm{O}$ (RSOF-Tm), and $\left[\mathbf{1}^{4+} \cdot(\mathbf{2})_{5} \cdot \mathrm{Lu}_{2} \cdot 8 \mathrm{H}_{2} \mathrm{O}\right] \cdot 22 \mathrm{H}_{2} \mathrm{O}$ (RSOF-Lu), all contain interlocked struts and proved to be isomorphous.

The five RSOFs described in this report were prepared by slow diffusion in a three-layer solution setup. Here, an aqueous solution containing 2 molar equiv. of the nitrate salt of the cation in question $\left(\mathrm{M}\left(\mathrm{NO}_{3}\right)_{3} ; \mathrm{M}=\mathrm{Y}(\mathrm{III}), \mathrm{Gd}(\mathrm{III}), \mathrm{Er}(\mathrm{III}), \mathrm{Tm}(\mathrm{III})\right.$ or Lu(III), was made up and placed in a small vial. This was layered with a mixture of DMF and water $(1: 1, \mathrm{v} / \mathrm{v})$, and then further layered with a mixture consisting of 1 molar equiv. of $\mathbf{1}^{4+} \cdot 4 \mathrm{PF}_{6}^{-}, 5$ molar equiv. of $2 \cdot 2 \mathrm{H}^{+}$, and 10 molar equiv. of $\mathrm{NMe}_{4} \mathrm{OH}$ dissolved in DMF and water $(1: 1, \mathrm{v} / \mathrm{v})$. Using this approach, single crystals suitable for X-ray diffraction analysis were generally obtained in five days ( $c f$. ESI $\dagger$ ). The resulting structures were used to confirm the presence of rotaxane subunits that contain Y(III), Gd(III), $\operatorname{Er}(\mathrm{III}), \mathrm{Tm}(\mathrm{III})$ or $\mathrm{Lu}(\mathrm{III})$, as well as equivalents of $\mathbf{2}$, both as the threaded species and as stopper subunits (Fig. 2). The individual rotaxanes self-associate via multiple strong intermolecular hydrogen bonds and $\pi \cdots \pi$ donoracceptor interactions to form what is an overall 3D framework (i.e., RSOF-M, M = Y, Gd, Er, Tm or Lu).
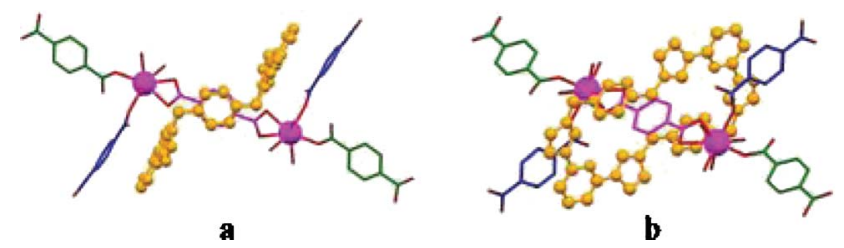

Fig. 2 Schematic representations, in stick form, of the rotaxane subunits present in the solid state structure of $\left[\mathbf{1}^{4+} \cdot(\mathbf{2})_{5} \cdot \mathrm{Er}_{2} \cdot 8 \mathrm{H}_{2} \mathrm{O}\right] \cdot 19 \mathrm{H}_{2} \mathrm{O}$ (RSOF-Er), as determined from single crystal $\mathrm{X}$-ray diffraction analysis. Similar structures were found for $\left[\mathbf{1}^{4+} \cdot(\mathbf{2})_{5} \cdot \mathrm{Y}_{2} \cdot 8 \mathrm{H}_{2} \mathrm{O}\right] \cdot 31 \mathrm{H}_{2} \mathrm{O}(\mathrm{RSOF}-\mathrm{Y})$, $\left[\mathbf{1}^{4+} \cdot(\mathbf{2})_{5} \cdot \mathrm{Gd}_{2} \cdot 8 \mathrm{H}_{2} \mathrm{O}\right] \cdot 22 \mathrm{H}_{2} \mathrm{O} \quad(\mathrm{RSOF}-\mathrm{Gd}), \quad\left[\mathbf{1}^{4+} \cdot(\mathbf{2})_{5} \cdot \mathrm{Tm}_{2} \cdot 8 \mathrm{H}_{2} \mathrm{O}\right] \cdot 32 \mathrm{H}_{2} \mathrm{O}$ (RSOF-Tm), and $\left[\mathbf{1}^{4+} \cdot(\mathbf{2})_{5} \cdot \mathrm{Lu}_{2} \cdot 8 \mathrm{H}_{2} \mathrm{O}\right] \cdot 22 \mathrm{H}_{2} \mathrm{O}(\mathrm{RSOF}-\mathrm{Lu})$.
The single crystal X-ray diffraction structures of RSOF-M $(\mathrm{M}=$ $\mathrm{Y}, \mathrm{Gd}, \mathrm{Er}, \mathrm{Tm}$ or $\mathrm{Lu}$ ) revealed the presence of 3D supramolecular organic frameworks within the crystalline lattice structure. These frameworks, which are essentially identical in the case of all three cations, are comprised of individual $\left[\mathbf{1}^{4+} \cdot(\mathbf{2})_{5} \cdot \mathrm{M}_{2} \cdot 8 \mathrm{H}_{2} \mathrm{O}\right](\mathrm{M}=$ Y(III), Gd(III), Er(III), Tm(III) or Lu(III)) rotaxane subunits. The core of this overall salt structure can be considered as consisting of two separate parts, namely a) a tetracationic macrocycle $\mathbf{1}^{4+}$ and b) a tetraanionic dumbbell shaped cluster formed from five molecules of 2, two coordinating metal cations, and eight water molecules (cf. Fig. 2). These subunits are characterized by strong $\pi-\pi$ donor-acceptor interactions, as evidenced by the short interatomic distance (less than $3.5 \AA$ ) between the benzene rings in $\mathbf{1}^{4+}$ and the $\pi$-surface of the inserted dianion $2(\mathrm{O}(1)$ in RSOF-M. (Note: the cations Y(III), Gd(III), Er(III), Tm(III) or Lu(III) are highlighted in magenta in Fig. 2 to aid in visualization.)

Intermolecular $\mathrm{C}-\mathrm{H} \cdots$ anion hydrogen bonding also plays an important role in stabilizing the RSOF structures. These hydrogen bonds are inferred from the short distances (less than $3 \AA$ ) between $\mathrm{O}(1)$ on $\mathbf{2}$ and $\mathrm{C}(15)$ on $\mathbf{1}^{4+}$ in RSOF-Er. Similar interactions were observed for the other RSOF-M structures $(\mathrm{M}=\mathrm{Y}, \mathrm{Gd}$, Tm or Lu) $(c f$. ESI $\dagger)$. In all five cases, the "tips" of the interpenetrated dianions protrude from the macrocyclic rings and are linked to the adjacent "tops" of the non-interpenetrated dicarboxylate anions (labelled with dark blue and green colors in Fig. 2 and 3) via M(III) cation bridges. The two non-interpenetrated anions are located in different chemical environments. Four water molecules also act as ligands and work in tandem with the three anions to complete a coordination number of 8 about the metal cations ( $c f$. Fig. 3a).

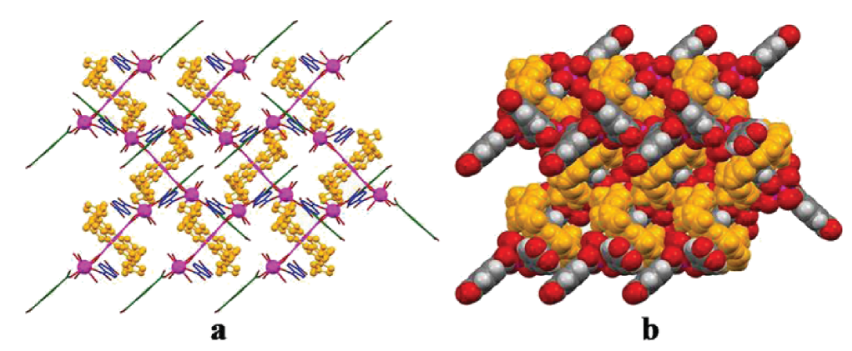

Fig. 3 Single crystal X-ray structure of $\left[\mathbf{1}^{4+} \cdot(2)_{5} \cdot \operatorname{Er}_{2} \cdot 8 \mathrm{H}_{2} \mathrm{O}\right] \cdot 19 \mathrm{H}_{2} \mathrm{O}$ (RSOF-Er) displayed in stick (a) and space-filling (b) forms so as to highlight the overall $3 \mathrm{D}$ framework; identical features are seen in the case of $\left[\mathbf{1}^{4+} \cdot(\mathbf{2})_{5} \cdot \mathrm{Y}_{2} \cdot 8 \mathrm{H}_{2} \mathrm{O}\right] \cdot 31 \mathrm{H}_{2} \mathrm{O}$ (RSOF-Y), $\left[\mathbf{1}^{4+} \cdot(\mathbf{2})_{5} \cdot \mathrm{Gd}_{2} \cdot 8 \mathrm{H}_{2} \mathrm{O}\right] \cdot 22 \mathrm{H}_{2} \mathrm{O} \quad(\mathrm{RSOF}-\mathrm{Gd}), \quad\left[\mathbf{1}^{4+} \cdot(\mathbf{2})_{5} \cdot \mathrm{Tm}_{2} \cdot 8 \mathrm{H}_{2} \mathrm{O}\right] \cdot 32 \mathrm{H}_{2} \mathrm{O}$ (RSOF-Tm), and $\left[\mathbf{1}^{4+} \cdot(\mathbf{2})_{5} \cdot \mathrm{Lu}_{2} \cdot 8 \mathrm{H}_{2} \mathrm{O}\right] \cdot 22 \mathrm{H}_{2} \mathrm{O}(\mathrm{RSOF}-\mathrm{Lu})$.

In the lattice, the non-interpenetrated anions act as hydrogen bond acceptors, interacting with the water ligands on the neighboring rotaxane subunits via multiple strong intermolecular hydrogen bonds, as inferred from the short distances involved (less than $2.7 \AA$ ). The rotaxane subunits associate further through a series of hydrogen bonding, metal-coordination, and $\pi-\pi$ donoracceptor interactions into an extended 2D network ( $c f$. ESI $\dagger$ ). The terephthalate anions and co-crystallized water molecules are linked via hydrogen bonds. Two different 2D layers are then linked via hydrogen bonding interactions involving the noninterpenetrated terephthalate dianions and water molecules. To aid in visualization, the key terephthalate oxygen atom involved, $\mathrm{O}(7)$, is shown in dark blue in Fig. 2 and 3. 
Interactions between the $2 \mathrm{D}$ layers in gives rise to the $3 \mathrm{D}$ rotaxane supramolecular organic framework as observed in the single crystals structures of all five RSOF-M ( $\mathrm{M}=\mathrm{Y}, \mathrm{Gd}, \mathrm{Er}$, Tm or Lu) (cf. Fig. 5 and ESI†). On the basis of the structural parameters, strong $\pi \cdots \pi$ donor acceptor interactions between the rotaxane units present in neighboring layers were also inferred; presumably, they play a role in stabilizing the overall structure.
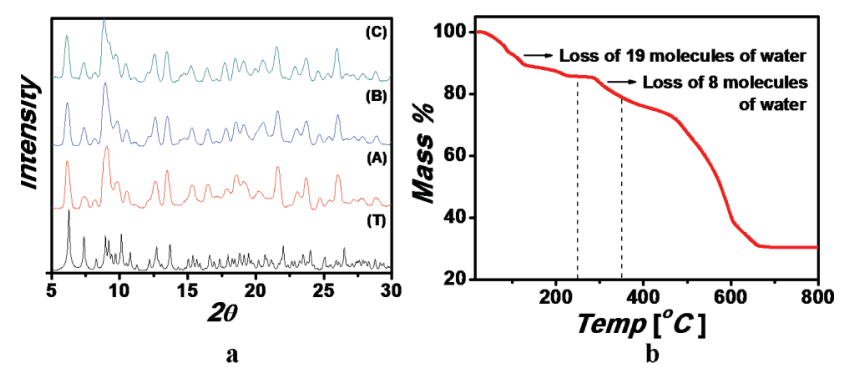

Fig. 4 (a) PXRD patterns of the metallic, rotaxane-containing supramolecular organic framework $\left[\mathbf{1}^{4+} \cdot(\mathbf{2})_{5} \cdot \mathrm{Er}_{2} \cdot 8 \mathrm{H}_{2} \mathrm{O}\right] \cdot 19 \mathrm{H}_{2} \mathrm{O}$ (RSOF-Er) samples obtained by crystallization (A), as calculated from the crystallographic coordinates $(\mathrm{T})$, produced via a bulk preparation procedure (B), and after subjecting to heating to $220{ }^{\circ} \mathrm{C}$ for $20 \mathrm{~min}(\mathrm{C})$. (b) Thermogravigram of $\left[\mathbf{1}^{4+} \cdot(2)_{5} \cdot \mathrm{Er}_{2} \cdot 8 \mathrm{H}_{2} \mathrm{O}\right] \cdot 19 \mathrm{H}_{2} \mathrm{O}$ (RSOF-Er) showing the percent weight loss as a function of temperature. Conditions: Nitrogen atmosphere, heating rate of $10^{\circ} \mathrm{C} \mathrm{min}{ }^{-1}$.
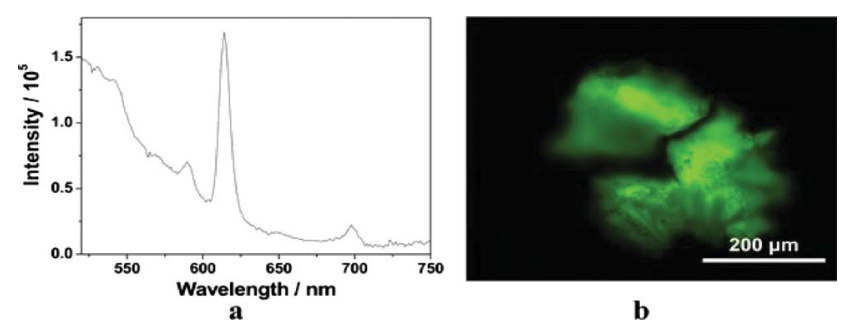

Fig. 5 Solid photoluminescence spectra (a) and luminescence microscopy photo (b) of the single crystal of $\left[\mathbf{1}^{4+} \cdot(2)_{5} \cdot \mathrm{Lu}_{2} \cdot 8 \mathrm{H}_{2} \mathrm{O}\right] \cdot 22 \mathrm{H}_{2} \mathrm{O}$ (RSOF-Lu).

For the purposes of preliminary analysis, one of the five structurally analogous RSOFs, $\left[\mathbf{1}^{4+} \cdot(\mathbf{2})_{5} \cdot \mathrm{Er}_{2} \cdot 8 \mathrm{H}_{2} \mathrm{O}\right] \cdot 19 \mathrm{H}_{2} \mathrm{O}$ (RSOF-Er), was prepared on a large scale. This was done using a one-pot procedure that involved co-crystallization of all the constituent precursor elements ( $c f$. ESI $\dagger$ ). The material obtained in this way (in roughly $71 \%$ yield) proved analogous to that generated on small scale, as inferred from comparative powder X-ray diffraction (PXRD) analysis ( $c f$. Fig. 4, traces (A) and (B) and the ESI $\left.\dagger^{\dagger}\right)$. A good concordance between the observed and calculated patterns was also seen for both the crystalline and bulk samples (cf. Fig. 4, traces $(\mathrm{A})$ and $(\mathrm{T})$ ).

The bulk sample of RSOF-Er was subject to thermogravimetric (TGA) analysis (Fig. 4). It proved thermally stable upon heating to ca. $220^{\circ} \mathrm{C}$ for $20 \mathrm{~min}$ and was found to retain its structure after loss of the water molecules originally present in the crystal lattice, as determined by thermogravimetric analysis (TGA) and powder Xray diffraction (PXRD) analyses ( $c f$. Fig. 4 and ESI $\dagger$ ). On this basis we conclude that the key rotaxane-containing supramolecular organic frameworks are thermally stable (i.e., crystallinity is retained after removal of the co-crystallized solvent, water). This stability is thought to reflect the presence of interlocked rotaxane moieties within the overall RSOF structure.

A noteworthy feature of the TGA curve is the presence of decreases in the weight percent that can be ascribed to the systematic loss of water molecules. Based on the single crystal X-ray diffraction analysis, RSOF-Er contains two distinct kinds of water molecules, namely those coordinated to the $\operatorname{Er}($ III) centers and those that are present as waters of crystallization. The latter guest waters are removed by the time heating to $c a .250{ }^{\circ} \mathrm{C}$ is complete. While the inherently labile nature of these solvent waters makes quantitative analysis necessarily imprecise (slow evaporation can take place in the absence of heating), at this point in the TGA analysis a weight decrease of $c a .14 .4 \%$ has occurred. This corresponds to a theoretical value of $15.1 \%$ expected for 19 water molecules. Further heating then leads to additional weight loss, which is ascribed to the loss of coordinated waters. For instance, by $c$ a. $350{ }^{\circ} \mathrm{C}$ the total weight loss is $21.0 \%$, a value that may be compared with the $21.4 \%$ decrease expected for the total loss of 27 water molecules. This corresponds to a total loss of approximately 27 water molecules. Further heating then leads to weight losses that are thought to reflect collapse of the framework structure (cf. Fig. 4b).

The bulk RSOF-Er sample was also subject to BET (Brunauer, Emmett and Teller theory) surface area analysis. These latter measurements revealed gas absorption profiles consistent with a compact structure lacking large, well-defined voids. Specifically, this RSOF acted as a low porosity material that displays multilayer adsorption behavior, as determined from an $\mathrm{N}_{2}$ adsorption isotherm measured at $77 \mathrm{~K}$ ( $c f$. ESI $\dagger)$. Such findings are in accord with the compact structure seen in the solid state, as reflected in Fig. 3b. The lack of free void space in RSOF-Er is ascribed to the presence of the rotaxane subunits, which occupy the intrasubunit space that might otherwise be expected in an analogous 3Dframework characterized by a lower level of structural complexity.

The rotaxane-containing frameworks reported herein all contain rare-earth cations. This led us to consider that they might display species-specific optical features. In an effort to test this hypothesis, three of the RSOFs of this study (viz. RSOF$\mathrm{Y}$, RSOF-Er and RSOF-Lu) were analyzed via single crystal luminescence spectroscopy. ${ }^{17}$

All three samples displayed weak green luminescence as revealed by luminescence microscopic photography. In the case of RSOF$\mathrm{Y}$ and RSOF-Lu weak peaks ascribable to the rare-earth cations were observed in the photoluminescence spectra upon excitation at $310 \mathrm{~nm}$ ( $c f$. Fig. 5 and ESI $\dot{\dagger}$ ). In the case of these latter two samples, as well as RSOF-Er, the actual spectra were dominated by a broad band that tails off from 450 to $750 \mathrm{~nm}$, and which has its origin in the interaction between $\mathbf{1}^{4+}$ and $\mathbf{2}$ as inferred from control studies involving crystals of $\mathbf{1}^{4+} \cdot(\mathbf{2})_{2} \cdot 10 \mathrm{H}_{2} \mathrm{O}(c f$. ESI $\dagger)$.

\section{Conclusions}

In summary, the synthesis of metal-containing rotaxanated supramolecular organic frameworks (RSOFs) incorporating three different types of supramolecular interactions is described. The systems in question, RSOF-Y, RSOF-Gd, RSOF-Er, RSOF$\mathrm{Tm}$ and RSOF-Lu, utilize anionic building blocks to fulfil at least three disparate functions; they act as interpenetrated species, serve as metal-complexing ligands, and stabilize hydrogen bonding 
interactions. The resulting RSOFs can be prepared easily and in good yield via a simple one-pot self-assembly procedure. This leads us to predict that these or other systems incorporating interlocked subunits could have a role to play in the construction of complex supramolecular frameworks whose $3 \mathrm{D}$ structures are rationally designed and experimentally controlled.

\section{Acknowledgements}

The authors are grateful to the National Science Foundation (grant no. CHE 1057904 to J.L.S. and grant no. 0741973 for the X-ray diffractometer), the Robert A. Welch Foundation (grant F1018 to J.L.S.) and the Korean World Class University (WCU) program (grant R32-2010-000-10217-0) for financial support.

\section{Notes and references}

1 (a) S. J. Loeb, Chem. Soc. Rev., 2007, 36, 226-235; (b) M. W. Hosseini, Acc. Chem. Res., 2005, 38, 313-323; (c) S. Mann, Nature, 1993, 365, 499-505; (d) M. W. Hosseini, CrystEng Comm, 2004, 6, 318322

2 (a) M. Simard, D. Su and J. D. Wuest, J. Am. Chem. Soc., 1991, 46984700; (b) K. E. Maly, N. Malec, J.-H. Fournier, P. Rodríguez-Cuamatzi, T. Maris and J. D. Wuest, Pure Appl. Chem., 2006, 78, 1305-1321; (c) M. C. Etter, Acc. Chem. Res., 1990, 23, 120-126; (d) S. Subramanian and M. J. Zaworotko, Coord. Chem. Rev., 1994, 137, 357-401.

3 (a) A. J. Blake, N. R. Champness, P. Hubberstey, W.-S. Li, M. A. Withersby and M. Schroder, Coord. Chem. Rev., 1999, 183, 117-138; (b) M. Eddaoui, D. B. Moler, H. Li, B. Chen, T. M. Reinke, M. O'Keefe and O. M. Yaghi, Acc. Chem. Res., 2001, 34, 319-330; (c) B. Moulton and M. J. Zaworotko, Chem. Rev., 2001, 101, 1629-1658.

4 (a) M. W. Hosseini and A. De Cian, Chem. Commun., 1998, 727-733; (b) F. Hajek, E. Graf, M. W. Hosseini, X. Delaigue, A. De Cian and J. Fischer, Tetrahedron Lett., 1996, 37, 1401-1404.

5 (a) M. W. Hosseini, Actualite Chimique, 2011, 348-349, 36-40; (b) J.-M. Lehn, C. R. Chim., 2011, 14, 348-361.
6 (a) J. Y. Lu, Coord. Chem. Rev., 2003, 246, 327-347; (b) O. R. Evans, R.-G. Xiong, Z. Wang, G. K. Wong and L. Wenbin, Angew. Chem., Int. Ed., 1999, 38, 536-538.

7 S. J. Dalgarno, P. K. Thallapally, J. L. Barbour and J. L. Atwood, Chem. Soc. Rev., 2007, 36, 236-245.

8 (a) J. R. Long and O. M. Yaghi, Chem. Soc. Rev., 2009, 38, 1213-1214; (b) A. U. Czaja, N. Trukhan and U. Muller, Chem. Soc. Rev., 2009, 38, 1284-1293; (c) S. L. James, Chem. Soc. Rev., 2003, 32, 276-288.

9 (a) W. Yang, A. Greenway, X. Lin, R. Matsuda, A. J. Blake, C. Wilson, W. Lewis, P. Hubberstey, S. Kitagawa, N. R. Champness and M. Schroder, J. Am. Chem. Soc., 2010, 132, 14457-14469; (b) Y.-Y. Shi, J. Sun, Z.-T. Huang and Q.-Y. Zheng, Cryst. Growth Des., 2010, 10, 314-320.

10 (a) S. Ferlay and M. W. Hosseini, Funct. Supramol. Archit., 2011, 1, 195-232; (b) N. Malek, T. Maris, M. Simard and J. D. Wuest, J. Am. Chem. Soc., 2005, 127, 5910-5916; (c) J. Mendez, R. Caillard, G. Otero, N. Nicoara and J. A. Martin-Gago, Adv. Mater., 2006, 18, 2048-2052.

11 (a) L. Fang, M. A. Olson, D. Benitez, E. Tkatchouk, W. A. Goddart III and J. F. Stoddart, Chem. Soc. Rev., 2010, 39, 17-29; (b) G. Shill, in Catenanes, Rotaxanes, and Knots., Academic Press, 1971; (c) D. B. Amabilino and J. F. Stoddart, Chem. Rev., 1995, 95, 2725-2828; (d) F. M. Raymo and J. F. Stoddart, Chem. Rev., 1999, 99, 1643-1663; (e) J.-P. Collin, V. Heitz and J.-P. Sauvage, Top. Curr. Chem., 2005, 262, 29-62; $(f)$ E. R. Kay, D. A. Leigh and F. Zerbetto, Angew. Chem., Int. Ed., 2007, 46, 72-191.

12 (a) J. F. Stoddart, Acc. Chem. Res., 2001, 34, 410-411; (b) A. R. Pease, J. O. Jeppesen, J. F. Stoddart, Y. Luo, C. P. Collier and J. R. Heath, Acc. Chem. Res., 2001, 34, 433-444.

13 (a) V. N. Vukotic and S. J. Loeb, Chem.-Eur. J., 2010, 16, 13630-13637; (b) D. J. Hoffart and S. J. Loeb, Angew. Chem., Int. Ed., 2005, 44, 901-904; (c) H. Wu, H.-Y. Liu, Y.-Y. Liu, J. Yang, B. Liu and J.-F. Ma, Chem. Commun., 2011, 47, 1818-1820.

14 H.-Y. Gong, B. M. Rambo, E. Karnas, V. M. Lynch and J. L. Sessler, Nat. Chem., 2010, 2, 406-409.

15 H.-Y. Gong, B. M. Rambo, E. Karnas, V. M. Lynch, K. M. Keller and J. L. Sessler, J. Am. Chem. Soc., 2011, 133, 1526-1533.

16 H.-Y. Gong, B. M. Rambo, W. Cho, V. M. Lynch, M. Oh and J. L. Sessler, Chem. Commun., 2011, 47, 5973-5975.

17 C. Yang, O. Elbjeirami, S. Chammi, C. S. Palehepitiya Gamage, H. V. R. Dias and M. A. Omary, Chem. Commun., 2011, 47, 7434-7436. 